\title{
One side strengthening of masonry walls with CFRP
}

\author{
N. Torunbalci ${ }^{1}$, E. Onar ${ }^{2} \&$ F. Sutcu ${ }^{1}$ \\ ${ }^{I}$ Faculty of Architecture, Istanbul Technical University, Turkey \\ ${ }^{2}$ Institute of Science and Technology, Istanbul Technical University, \\ Turkey
}

\begin{abstract}
Masonry structures may exhibit inferior performance against lateral loads, such as those induced by earthquakes. In this context, it is crucial for such structures of historical value to increase their seismic performances in order to be protected against the earthquakes. This study deals with the empirical assessment of strengthening the masonry structures whose structural walls are constructed with bricks. In this study, conventional brick walls are strengthened using CFRP stripe and textile materials in different forms on one side and the target is to determine the effect of this strengthening on the behaviours and the strength of the walls on an empirical approach.
\end{abstract}

Keywords: strengthening masonry, fibre reinforced polymers, brick masonry, retrofitting.

\section{Introduction}

Masonry structures are under risk in earthquake zones. In this context, it is crucial to have the existing masonry structures protected against earthquakes by increasing their performance levels.

Strengthening should be provided for the structures to maintain their structural integrity that may not have been taken into consideration during their original design or construction, to increase their load-bearing capacities as a result of the change in their functional usage, eliminate the defects attributed to incorrect or insufficient application during construction and to supplement the load-bearing capacities that may be reduced as a result of the corrosion and wear in the course of time. The popular method is strengthening by application of the 
shotcrete on both surfaces of the walls coated with the steel mesh reinforcement. On the other hand, such strengthening by application of the shotcrete is not free of any further problems in practice to have the desired design strength. Where the standard concrete is used, however, placing and compacting the concrete prove to be difficult due to the insufficient size of the formwork. Increasing the thickness of the concrete layer can eliminate the problem, but, this in turn gives rise to undesirable loss of the footing area. Such type of strengthening is therefore not preferred, even if it greatly contributes to the structural performance. Where self-compacting concrete is used, the majority of the aforementioned problems are eliminated, however, this time the original architecture of the structure is jeopardized.

Another method still under investigation involves the strengthening of existing structural walls using FRP materials. Providing practical and efficient solutions with the use of the concrete and steel material proves to be difficult, FRP strengthening materials obtained by the mixture of carbon, glass and aramide with the reinforced resin provide higher tensile strength than the steel due to its fine, corrosive resistant and durable fibrous structure. Application while the structure is in use is also possible without endangering the sectional forms of the strengthened portions of the structures. Available in stripe/laminated or textile form, FRP is applied on the wall surface by the epoxy adhesive. The fibres take up the loading, while the epoxy adhesive ensures homogenous load distribution between the fibres, protecting them from the environmental effects. Although under investigation, however, they have undesirable properties as well, including inferior elasticity module and insufficient properties under creep and fatigue loading. However, this method might effectively be used in strengthening the structures of historical value due to its virtue of preserving original architecture of the structures to a great extent.

Various experimental and analytical studies have been performed on the behaviour of the structural masonry walls under in plane, out of plane and axial loading. In an experimental work performed to determine the fibre composite strength applied on the masonry structure, conformity of the fibre material, anchorage lengths and behaviour under shear loading, [2] 37 brick wall specimens in $64 \mathrm{~mm} \times 102 \mathrm{~mm} \times 216 \mathrm{~mm}$ size are strengthened by FRP material in specified width and length in inclinations of $0^{\circ}$ and $45^{\circ}$. The study determines that when subject to static loading, the strength and rigidity of the tested specimens increase to a great extent and that the fibres' angular inclination with respect to the load plane has significant effect on the rigidity, however, no such effect is observed on the wall strength. In another study again undertaken by Ehsani et al. [3], the investigation is performed on the behaviour of the structural walls subject to loading acting out of the loading plane of the walls that are strengthened with CFRP materials as stripes placed in orthogonal directions to the joints on both surfaces. The study determines that CFRP stripe materials prove to be a good alternative for strengthening the structural brick walls against the lateral loads in that energy dissipation capacities are improved. Albert et al. [4] conducted the experimental works to determine the behaviour of the structural brick walls strengthened using carbon and glass FRPs under cyclic 
axial compressive loading, with various FRP forms, quantities and number of layers. Also providing the analyses on out of plane lateral loading, the study establishes that the performance of pre-damaged and non-damaged brick wall specimens strengthened using carbon fibre stripes are much better than those strengthened using glass fibres. It is also stated that strengthening using FRP is an alternative method to the existing retrofitting methods. Tan and Patoary [5] in their works strengthen the brick wall specimens using FRP under three different anchoring methods. In strengthening, they use the specimens in $1000 \mathrm{~mm} \mathrm{x}$ $1000 \mathrm{~mm} \times 110 \mathrm{~mm}$ size, with joints of $10 \mathrm{~mm}$. The results of experiments prove that the increase in out-of-plane strengths of the retrofitted brick wall specimens is significant. Fracture are observed in the brick wall specimens without reinforcement due to bending, whereas retrofitted ones underwent four different failure modes. Namely, the shear failure along the bricks, weakening of the bond between FRP and brick wall surfaces, formation of bending cracks and formation of tensional failure of FRP strengthening materials. In a study where 42 wall specimens subject to in-plane loading with the angle between the horizontal joints and axial force being $0^{\circ}, 30^{\circ}, 45^{\circ}, 60^{\circ}$ and $90^{\circ}$ reinforced by the laminated Glass FRP Hamid et al. [6], it is determined that FRP has significant influence on increasing the strength and failure mode as well as extension of the rigidity of the wall. They also determine that, compared with specimens without reinforcement, the compressive strength is increased by $160-500 \%$. Krevaikas and Triantafillou [7] conduct a study where 42 brick wall specimens of $115 \mathrm{mmx}$ $115 \mathrm{~mm}, 172.5 \mathrm{~mm} \times 115 \mathrm{~mm}$ and $230 \mathrm{~mm} \times 115 \mathrm{~mm}$ sizes are reinforced with 1,2 and 3 layers of CFRP stripes and 5 layers of GFRP and their behaviours are investigated under axial loading. It is determined, upon the experiment, that the load-bearing capacities and strains of the brick wall specimens are considerably increased. In particular, the formation of the wrap regions at the wall corners improves the stress and strength properties.

\section{Purpose and scope of experimental works}

In this study conventional brick walls are strengthened using CFRP stripe and textile materials on one side and the target is determining the effect of this strengthening on the behaviours and the strength of the walls on an experimental approach. The brick wall samples were mounted on the testing rig in such a way so that the bed joints formed an angle of $45^{\circ}$ with the direction of vertical loading. Loading is exerted onto the concrete shoes constructed on opposing corners of the brick masonry specimens [1].

Some of the specimens were pre-damaged and the comparisons were made for the change in the load-bearing capacities and behaviours following the strengthening. Within the scope of this study, it is also aimed to provide comparative analysis on, the effects of the form and quantity of CFRP and inspection of the displacements and failure modes, for which relevant specimen series were formed to correspond the resulting alternatives for respective parameters. 
Table 1: $\quad$ CFRP material and adhesive properties.

\begin{tabular}{lc}
\hline Parameter & Details \\
\hline CFRP Stripe & 3000 \\
Tensile Ultimate Strength (MPa) & 1.8 \\
Elongation at break, $\varepsilon_{\mathrm{u}}(\%)$ & 165000 \\
Tensile Modulus MPa & 1.2 \\
Thickness of Layer $(\mathrm{mm})$ & \\
& \\
CFRP Textile & 3430 \\
Tensile Ultimate Strength $(\mathrm{MPa})$ & 1.5 \\
Elongation at break, $\varepsilon_{\mathrm{u}}(\%)$ & 23000 \\
Tensile Modulus MPa & $165 \mathrm{micron}$ \\
Thickness of Layer $(\mathrm{mm})$ & \\
& \\
Stripe adhesive & 6 \\
Compressive Strength $(\mathrm{MPa})$ & \\
& \\
Textile adhesive & 50 \\
Tensile Strength $(\mathrm{MPa})$ & 80 \\
Compressive Strength $(\mathrm{MPa})$ & 3000 \\
Tensile Modulus MPa & \\
\hline
\end{tabular}

\section{Test plan}

\subsection{Material used to strengthen the brick wall specimens}

Two types of CFRP material, namely stripe and textile CFRP, were used in strengthening of the brick wall specimens.

Stripe CFRP was $10 \mathrm{~cm}$ wide and $1.2 \mathrm{~mm}$ thick laminate form. The unidirectional textile CFRP was $50 \mathrm{~cm}$ wide and 165 micron thick. CFRP were applied on the specimen surfaces with their own adhesives. The two-part epoxy resin adhesives were prepared according to the volumetric proportion by the manufacturer. CFRP material and adhesive properties are given in Table 1.

After the surface preparation the adhesive was impregnated into the CFRP textile fibres by pressing the roll prior to final coat of adhesive onto the fibre layer, while CFRP stripes were applied directly on the adhesive layer on the specimen surface.

\subsection{Brick wall properties and specimen groups}

The experiments are performed on plane brick wall specimens and brick wall specimens strengthened in different forms, using CFRP stripe/laminate and textile materials. In constructing the brick wall specimens, the mortar was used in cement: sand: water mixture ratio of 1:3.5:0.70. The mortar compressive strength was $15.63 \mathrm{MPa}$, whereas the clay bricks reduced in such size as to 
construct the brick wall specimens featuring the compressive strength of 18.92 MPa. The joint size of $0.5 \mathrm{~cm}$ is adopted in constructing the brick wall specimens.

The experiments consisted of 2 series with 6 brick wall specimens in the size of $185 \times 185 \times 45 \mathrm{~mm}$ provided for each series. Six brick wall specimens were used without strengthening as an additional series to represent unreinforced masonry walls (URM). The brick wall samples were mounted on the testing rig in such a way so that the bed joints formed an angle of $45^{\circ}$ with the direction of vertical loading on high-strength concrete shoes constructed on the specimens and overall displacements are measured by a transducer placed with $100 \mathrm{~mm}$ nominal length (Figure 1). Half of each series are subjected to pre-damaging process almost up to the level of the collapse. These specimens are then repaired with epoxy resin. Together with non-damaged specimens, these pre-damaged-andepoxy-repaired specimens are then loaded until the occurrence of the failure in three different strengthening series.

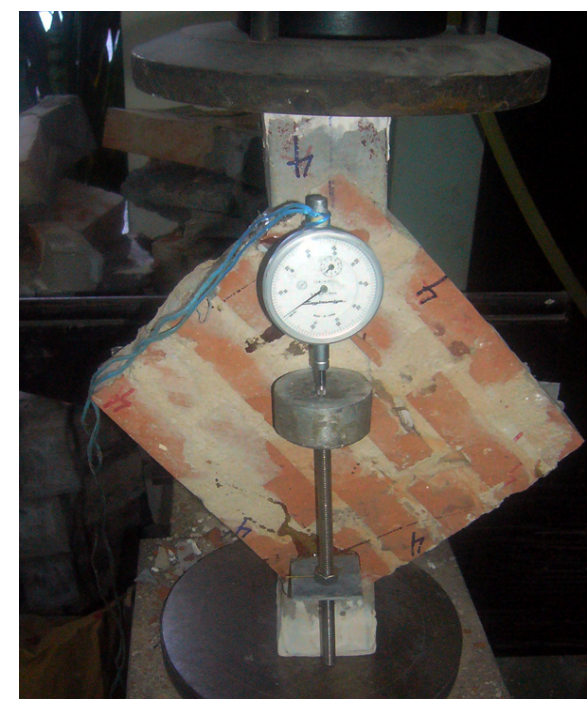

Figure 1: Brick wall specimens and test set up.

In Series 1, ready-made $25 \mathrm{~mm}$ wide FRP strips are applied first in the direction of the tensile stresses and then compressive stresses of brick wall specimens (Figure 2a).

For Series 2, however, uni-directional fabric sheet carbon FRPs are used of 165 micron thick. The textile CFRP is a cheaper material as compared to the laminated CFRP and therefore, the application by textile CFRPs is performed in order to keep all the cracks to be formed on the surfaces of the brick wall specimens under control (Figure 2b).

Plain brick wall specimens without pre-loading are nominated as URM=Unreinforced Masonry Wall, whereas brick wall specimens that are damaged and repaired by the epoxy material are nominated as D-ER=Damaged- 
Epoxy Retrofitted. The nomination of the FRP strengthened specimens in a series is as follows: $\mathrm{D}=$ Damaged, stands for pre-damaged brick wall specimens; $\mathrm{S}=\mathrm{Strip}$, for FRP in the strip form and $\mathrm{T}=$ Textile, for FRP in the textile form. Accordingly, D-S stands for the pre-damaged brick wall specimens strengthened using FRP strip. Likewise, ND-T stands for the non-damaged brick walls strengthened using textile FRP on one side.

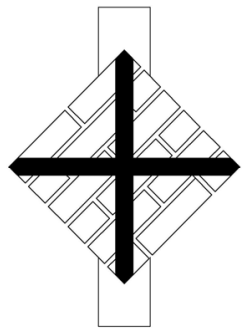

a) Series 1: CFRP stripe

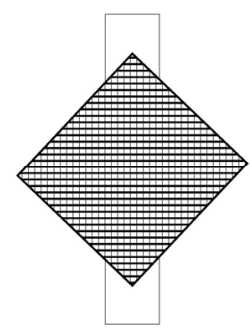

b) Series 2: CFRP textile

Figure 2: $\quad$ Strengthening forms.

\section{Results of experiments}

\subsection{Evaluation of URM wall specimens with repaired cracks}

In the course of determining in particular the behaviours of the brick wall specimens, 3 URM specimens are pre-damaged under axial compression and the cracks on the pre-damaged walls are repaired by the epoxy materials and subject to further loading. The maximum stress sustained by the specimens is calculated from eqn (1) in accordance with ASTM standards [8]:

$$
S_{S}=\frac{0.707 P}{A_{n}}
$$

where $S_{S}$ is the shear stress based on the net area, $P$ is the applied load and $A_{n}$ is the area of the specimen calculated as in eqn (2):

$$
A_{n}=\left(\frac{w+h}{2}\right) t n
$$

where $\mathrm{w}, \mathrm{h}$ and $\mathrm{t}$ are specimen width, height and thickness, respectively and $\mathrm{n}$ is the percentage of the area of the unit that is solid, as a decimal. Average compressive strengths of the URM walls subject to loading and after repaired by the epoxy materials following pre-damaging are determined as $0.79 \mathrm{MPa}$ and 1.22 $\mathrm{MPa}$, respectively. It is determined that the displacements of the plain brick walls are increased twice as much following the epoxy repair.

The failures on brick wall specimens consisted of the URM walls are in general along the joints of the walls. The fracture initiated along the bed joints propagate through the head joints, whereas the shear failures turn out to be the ultimate failure mode of the walls. In some cases, the fractures initiated at a joint 
propagated by breaking the bricks or the fractures initiated in the bricks propagated along the joints. The fractures on brick wall specimens repaired upon pre-damaging appear to be at different parts of the walls, rather than along the previous cracks repaired.

\subsection{Evaluations on series 1 specimens}

Series 1 consists of 6 brick wall specimens strengthened using CFRP stripes on one side. Table 2 provides the experimental data on the maximum compressive strength of the brick wall specimens where COV represents the coefficient of variation.

Table 2: $\quad$ Series 1 general experimental results.

\begin{tabular}{|c|c|c|c|c|c|}
\hline & & \multirow{2}{*}{$\begin{array}{c}\text { Test } \\
\text { Number }\end{array}$} & \multicolumn{3}{|c|}{ Max. compressive strength } \\
\hline & & & $\begin{array}{l}\text { Test result } \\
\text { (MPa) }\end{array}$ & $\begin{array}{c}\text { Average } \\
\text { (MPa) }\end{array}$ & $\begin{array}{c}(\mathrm{COV}) \\
\%\end{array}$ \\
\hline \multirow{3}{*}{ 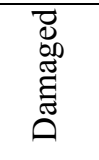 } & \multirow{3}{*}{ D-S } & 1 & 1.57 & \multirow{3}{*}{1.87} & \multirow{3}{*}{13.8} \\
\hline & & 2 & 2.00 & & \\
\hline & & 3 & 2.04 & & \\
\hline \multirow{5}{*}{ 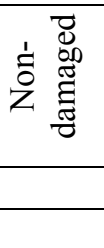 } & \multirow{3}{*}{ ND-S } & 1 & 1.44 & \multirow{3}{*}{1.59} & \multirow{3}{*}{15.5} \\
\hline & & 2 & 1.87 & & \\
\hline & & 3 & 1.44 & & \\
\hline & URM & & & 0.79 & 6.2 \\
\hline & D-ER & & & 1.22 & 32.2 \\
\hline
\end{tabular}

As compared with the plain brick walls, strengthening of brick wall specimens classified under Series1 significantly increase the strengths of the specimens. Furthermore, the increases in the degrees of the displacement are also significant (Figure 3).

For Series 1 specimens, the sample type exhibiting the highest failure ratings is D-S, whereas the specimen type featuring the lowest failure ratings is ND-S. According to the comparisons, it can be concluded that strengthening of the walls on single side significantly improve their performances, irrespective of whether they are pre-damaged or non-damaged. On the other hand, it is determined that the strengths of the specimens increases almost $100 \%$ as compared with that of the URM walls.

It is interesting to observe that pre-damaged specimens have better performance as compared with non-damaged ones. This is likely attributable to the effect of the epoxy materials used for repair of the pre-damaged specimens. The brick masonry wall specimens undergo the damage along their weakest portion when pre-loading to induce the damage on the plain brick walls. Repair of these cracks generally performed along the compression diagonal of brick 


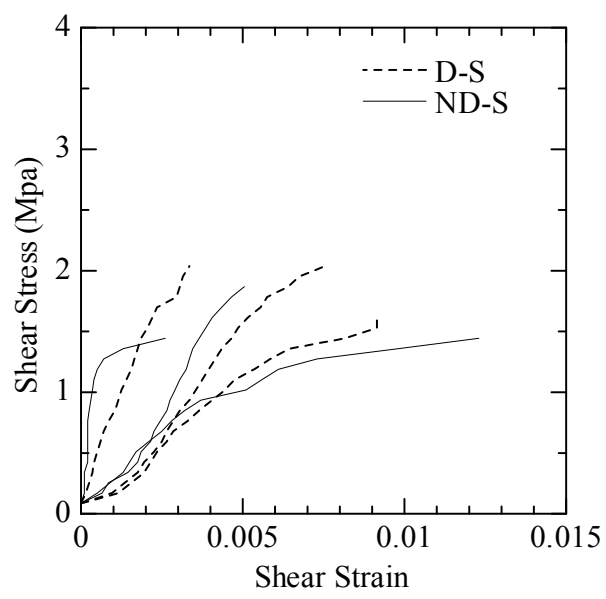

Figure 3: $\quad$ Series 1 shear stress-shear versus strain relation.

wall specimens, however, end up with significant increases in their strengths of these portions compared to the other portion of the specimens. Therefore, this process provides significant improvements in both failure and strain characteristics of the walls.

Prior to failure, the cracks propagate along the portion of brick wall specimens where no strengthening is provided. In some cases, the separations are observed between FRP strips and the surface of the specimens. Complete separation is, however, not observed in any one of the specimens. Notwithstanding the occasional cases where the plain brick walls undergo instantaneous failures under ultimate loading, no fragmentation is observed for the specimens strengthened with FRP strips.

\subsection{Evaluations on series 2 specimens}

Table 3 provides the experimental data on the maximum compressive strength of the specimens and the comparison of strengthened specimens to the plain brick walls and for the pre-damaged specimens repaired by the epoxy materials.

Series 2 specimens are provided with uni-directional fibre sheet CFRP strengthening in the tensional directions of the fibre axes. FRP strengthening covers all the surfaces of non-damaged, pre-damaged specimens strengthened on one side. The specimens with highest fracture loading rating within Series 2 specimens are D-T, whereas the specimens featuring the lowest fracture loading rating are ND-T.

It is observed, during the failure process, that the adherences between FRP textile and the wall surfaces are extremely crucial. It is concluded that the failure is induced on the brick internal structure.

No fragmentation is observed on strengthened specimens whatsoever. As a result of the internal forces generated within brick wall specimens, they either 
Table 3: $\quad$ Series 2 specimen general experimental results.

\begin{tabular}{|c|c|c|c|c|c|}
\hline & & \multirow[b]{2}{*}{$\begin{array}{c}\text { Test } \\
\text { Number }\end{array}$} & \multicolumn{3}{|c|}{ Max. compressive strength } \\
\hline & & & $\begin{array}{l}\text { Test result } \\
(\mathrm{MPa})\end{array}$ & $\begin{array}{c}\text { Average } \\
(\mathrm{MPa})\end{array}$ & $\begin{array}{c}(\mathrm{COV}) \\
\%\end{array}$ \\
\hline \multirow{3}{*}{ 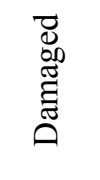 } & \multirow{3}{*}{ D-T } & 1 & 2.12 & \multirow{3}{*}{2.55} & \multirow{3}{*}{26.0} \\
\hline & & 2 & 2.21 & & \\
\hline & & 3 & 3.31 & & \\
\hline \multirow{5}{*}{ 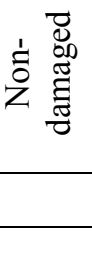 } & \multirow{3}{*}{ ND-T } & 1 & 1.53 & \multirow{3}{*}{1.67} & \multirow{3}{*}{10.6} \\
\hline & & 2 & 1.87 & & \\
\hline & & 3 & 1.61 & & \\
\hline & URM & & & 0.79 & 6.2 \\
\hline & D-ER & & & 1.22 & 32.2 \\
\hline
\end{tabular}

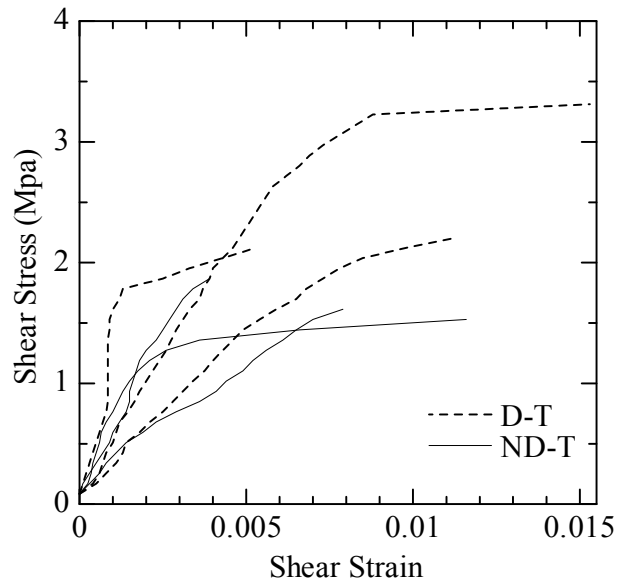

Figure 4: $\quad$ Series 2 shear stress-shear versus strain relation.

collapse or the cracks are propagated in the bricks along the joints, which give rise to brittle fracture at the failure. The shear stress-shear strain diagram is illustrated in Figure 4.

As it is the case for Series1 specimens, the increases in the strengths of the brick wall specimens strengthened only on one side imply that such strengthening improves the specimens' behaviour. Irrespective of the type of strengthening, the application only on one side ends up with the eccentricity due 
to the sectional geometry turned out to be asymmetrical, resulting with the premature failure.

\subsection{Overall comparison of experimental results}

Overall results of experiments are illustrated in Figure 5. The brick wall specimens strengthened using FRP textile perform better irrespective whether pre-damaged or non-damaged specimens are used. The strengths of Series 2 brick wall specimens turn out to be higher than those in Series1. This is in fact contrary to reasonable expectation that the non-damaged specimens would exhibit higher performance following strengthening, however, the results of the experiments are not any different than those obtained in previous comparisons. That is, the repair performed on pre-damaged specimens provides higher strength in excess its non-damaged status.

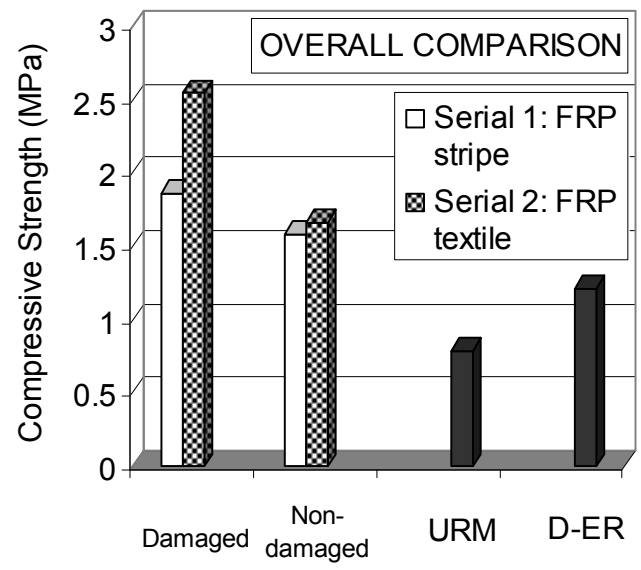

Figure 5: Overall comparison of experimental results.

It is the fact that the best improvements in the performances are obtained when strengthening using FRP textile, irrespective whether pre-damaged and non-damaged specimens are used. According to the comparative results, the highest fracture loading rating is achieved for D-T specimens, i.e., pre-damaged brick wall specimens strengthened by FRP textile on one side. The lowest failure loading rating is observed for ND-S brick masonry wall specimens, i.e., nondamaged specimens strengthened on one side using FRP strips. In regard to the displacements, the improvements of Series 2 specimens are better as compared with Series 1 specimens.

Affirmative effects of repair by the epoxy materials are observed in the comparative studies. When pre-loaded to induce the damage, the plain brick walls undergo the failure along their weakest part upon fracture, i.e., in most cases along the compression diagonal of the wall. Repaired using the epoxy materials, brick wall specimens exhibit higher strengths as compared with the 
plain brick walls prior to damaging. Therefore, it is determined, in all foregoing comparative analysis, that the pre-damaged-and-epoxy-repaired brick wall specimens exhibit higher load-bearing and deformation capacities.

\section{Conclusions and discussion}

Several observations are in general made in regard to repairing and strengthening of the masonry structural brick walls, which are remarkable enough to conduct further discussions following the experimental works on CFRP strengthening, using specific form and type FRP materials. In brick wall specimens strengthened using CFRP stripe and textile materials, it is observed that the fragmentations of the brick wall specimens into the pieces are effectively prevented as a result of wrapping obtained by the materials used for the purpose of the reinforcement. The plain brick walls usually collapse by formation of the cracks along the loading axis or else, in line with the joints or both the joints and the bricks. It is determined that strengthened brick wall specimens exhibit higher strengths and besides, they are not broken into pieces. Following strengthening, plain brick wall specimens undergo significant increases in their load-bearing capacities.

Although the strengthening is provided on one side of the brick wall specimens, the load-bearing capacities increased while tend to be dependant to numerous parameters. It is, however, not possible to state the exact ratios. The behaviour of the brick masonry wall specimens are closely related to status, character, and number of the cracks formed during pre-loading of the specimens and the quantity of the epoxy material used in repair of the cracks formed. Repair of these cracks generally formed along the compression diagonal however; end up with significant increases in their strengths of these portions compared to the other portion of the specimens. It is therefore likely that this is the main attribute defining both the failure and deformation behaviours of the specimens, rather than the type and quantity of the FRP used in strengthening. One another point to be emphasized here is that the sizes of the brick masonry wall specimens are small and therefore, the repaired portion of the wall covers the majority of the wall surface area irrespective how far care is observed. The bigger sizes of brick wall specimens are, the less likely to observe such effects and therefore, the epoxy materials will no more play as much significant role in strengthening.

Notwithstanding the lack of tendency of separation of CFRP stripe and textile materials from the surfaces of brick wall specimens due to loss of adherence, it is highly recommended in practice to roughen the surface of the repaired brick walls prior to the application of FRP strengthening.

The highest strengths are is obtained in CFRP textile strengthening applied on one side of the brick wall specimens, irrespective whether pre-damaged and nondamaged specimens are used. The improvements obtained by strengthening using CFRP stripe are pretty much the same, however CFRP textile strengthening provides better performance as compared with CFRP strip or. The highest performances are obtained for pre-damaged brick wall specimens strengthened, when FRP textile is used in strengthening. In regard to the higher 
cost of strengthening in case of CFRP textile, it is observed that CFRP strip strengthening is more cost effective.

In all strengthening applications using CFRP, the brick wall specimens' performances significantly improve. In particular, the adjoining buildings allow strengthening only on one side of the facing walls. Strengthening of such walls even if it is possible only for one side will provide significant improvement. CFRP is an effective alternative material to be used in strengthening of the masonry structures. The easiness and readiness in CFRP applications as well as its cost effectiveness and most of all architectural integrity obtained as compared with strengthening using concrete and steel rendering that causes significant change in the wall sections are the major advantages of this alternative.

\section{Acknowledgement}

The study presented here is sponsored by BASF-YKS Turkey. The authors acknowledge the financial support provided and the materials incorporated in the experiments.

\section{References}

[1] Onar, E. (2007). The Experimental study on strengthening of structural brick masonry walls using carbon fibre-reinforced polymers, M.Sc. Thesis, Institute of Science and Technology, Istanbul Technical University, 2007.

[2] Ehsani, M.R., Saadatmanesh, H. and Al-saidy, A. Shear behaviour of URM retrofitted with FRP overlays. Journal of Composites for Construction 1997; 1-1:117-25.

[3] Ehsani, M.R., Saadatmanesh, H. and Velazquez-Dimas, J.I. 1999. Behaviour of retrofitted URM walls under simulated earthquake loading. Journal of Composites for Construction 1999; 3-3:134-142.

[4] Albert, M.L., Elwi, A.E. and Cheng, R.J.J. Strengthening of unreinforced masonry walls using FRPs. Journal of Composites for Construction 2001;52:170-178.

[5] Tan, K.H. and Patoary, M. K. H. Strengthening of Masonry Walls against Out-of-Plane Loads Using Fibre-Reinforced Polymer Reinforcement. Journal of Composites for Construction 2004; 9-1:79-87.

[6] Hamid, A. A., El-Akhakhni, W. W., Hakam, Z. H. R. and Elgaaly, M. Behaviour of composite unreinforced masonry-fibre-reinforced polymer wall assemblages under in-plane loading. Journal of Composites for Construction 2005; 9-1:73-83.

[7] Krevaikas, T. D. and Triantafillou, T. C. Masonry confinement with fibrereinforced polymers. Journal of Composites for Construction 2005; 9-2:128135 .

[8] American Society for Testing and Materials (ASTM). (1981). "Standard test method for diagonal tension (shear) in masonry assemblages." Annual book of ASTM standards, E 519-81, Vol. 04.05 